\title{
Making a First Impression: Exploring What Instructors Do and Say on the First Day of Introductory STEM Courses
}

\begin{abstract}
A. Kelly Lane, ${ }^{\dagger}$ Clara L. Meaders, ${ }^{\ddagger}$ J. Kenny Shuman, $\$$ MacKenzie R. Stetzer, ${ }^{\prime \pi}$ Erin L. Vinson, "Brian A. Couch, ${ }^{\text {\$t+* Michelle K. Smith, }}{ }^{\text {\#t* }}$ and Marilyne Stains ${ }^{\dagger}$ Department of Biology Teaching and Learning, University of Minnesota, Minneapolis, MN 55455; "Department of Ecology and Evolutionary Biology, Cornell University, Ithaca, NY 14853; \$School of Biological Sciences, University of Nebraska- Lincoln, Lincoln, NE 68588; "Department of Physics and Astronomy and; "Maine Center for Research in STEM Education, University of Maine, Orono, ME 04469; "Department of Chemistry, University of Virginia, Charlottesville, VA 22904
\end{abstract}

\begin{abstract}
Student impressions formed during the first day of class can impact course satisfaction and performance. Despite its potential importance, little is known about how instructors format the first day of class. Here, we report on observations of the first day of class in 23 introductory science, technology, engineering, and math (STEM) courses. We first described how introductory STEM instructors structure their class time by characterizing topics covered on the first day through inductive coding of class videos. We found that all instructors discussed policies and basic information. However, a cluster analysis revealed two groups of instructors who differed primarily in their level of STEM content coverage. We then coded the videos with the noncontent Instructor Talk framework, which organizes the statements instructors make unrelated to disciplinary content into several categories and subcategories. Instructors generally focused on building the instructor-student relationship and establishing classroom culture. Qualitative analysis indicated that instructors varied in the specificity of their noncontent statements and may have sent mixed messages by making negatively phrased statements with seemingly positive intentions. These results uncovered variation in instructor actions on the first day of class and can help instructors more effectively plan this day by providing messages that set students up for success.
\end{abstract}

\section{INTRODUCTION}

Introductory science, technology, engineering, and math (STEM) courses often serve as undergraduate students' introduction to STEM disciplines and associated majors. These courses offer opportunities to foster a sense of belonging in students and establish students' science identities, especially for students from groups underrepresented in STEM (e.g., Schinske et al., 2016; Trujillo and Tanner, 2014; Sax et al., 2018). The first day of class may be an especially important time point, as it could be used to mitigate student concerns, establish course norms, communicate the importance of course activities, and increase student motivation through promoting positive student interactions and explanation of instructional choices (DiClementi and Handelsman, 2005; Nilson, 2010; Chasteen, 2013, 2020; Seidel and Tanner, 2013; Brazeal et al., 2016; Meaders et al., 2019).

There are abundant resources intended to help instructors design the first day of class. For example, many teaching and learning centers provide guidance on their websites and offer workshops on this topic. Peer-reviewed publications also provide support, such as suggestions for how instructors can introduce themselves and students to one another as well as recommendations for setting course expectations and motivating students (Anderson et al., 2011). However, empirical investigations about how college instructors are using the first day of class are lacking.
Jennifer L Momsen Monitoring Editor Submitted May 22, 2020; Revised Oct 20, 2020; Accepted Oct 29, 2020

CBE Life Sci Educ March 1, 2021 20:ar7

DOI:10.1187/cbe.20-05-0098

${ }^{\circledR}$ Co-first authors: These authors contributed equally to this work.

${ }^{" C} \mathrm{Co}-$ corresponding authors in alphabetical order: These authors contributed equally to this work.

*Address correspondence to: Brian A. Couch (bcouch2@unl.edu), Michelle K. Smith (mks274@cornell.edu), or Marilyne Stains (mstains@virginia.edu).

(c) 2021 Lane et al. CBE-Life Sciences Education (c) 2021 The American Society for Cell Biology.

This article is distributed by The American Society for Cell Biology under license from the author(s). It is available to the public under an Attribution-Noncommercial-Share Alike 3.0 Unported Creative Commons License (http:// creativecommons.org/licenses/by-nc-sa/3.0)

"ASCB®" and "The American Society for Cell Biology $\circledR^{\circ}$ are registered trademarks of The American Society for Cell Biology. 
To date, most studies exploring the first day of a course have used surveys to characterize student preferences for the structure and type of content provided and to understand how the first day impacts longer-term student impressions of the course. The results showed that students in multiple psychology courses preferred overviews of course requirements, faculty expectations, and information about how to get a good grade (e.g., grading standards, workloads, study tips; Perlman and McCann, 1999; Henslee et al., 2006; Eskine and Hammer, 2017). Students had mixed feelings about introducing content on the first day, with more than a quarter of students saying it was unpreferable (Perlman and McCann, 1999; Henslee et al., 2006). Although studies of student preferences did not show community building as a top preference for the first day (Perlman and McCann, 1999; Henslee et al., 2006; Eskine and Hammer, 2017), studies focused on community-building interventions showed positive impacts on students (Hermann et al., 2010; McGinley and Jones, 2014; Robinson, 2019). Students who participated in reciprocal interview ice-breaker activities in psychology courses reported that their instructors were more welcoming of student questions and felt that course expectations were more clearly communicated (Hermann et al., 2010; McGinley and Jones, 2014; Robinson, 2019). In one study, these positive impressions lasted throughout the semester and resulted in higher course evaluations for the sections that used the reciprocal interview activity than for the sections without the activity (Hermann et al., 2010). Another study of psychology students showed that students' impressions of the course and instructor after the first class period persisted until the end of the semester and were reflected on course evaluations (Laws et al., 2010).

The tone instructors set on the first day of class can also have lasting impact on students. In one study, students in an introductory psychology course were randomly assigned to watch a video of the professor on the first day (Wilson and Wilson, 2007). Half of the students watched a video of the professor using a positive tone, dismissing the class early, and assigning no homework. The other half watched a video of the same professor using an emotionless tone, teaching the full class period, and assigning homework. Students who experienced the first video reported greater motivation throughout the course and received significantly higher course grades than their peers who experienced the second video.

Despite the importance of the first day, to our knowledge, only one study provides insight on how instructors use this class time (Friedrich et al., 1993). In this study, 251 students of 145 instructors from across 31 academic departments, including both STEM and non-STEM disciplines, were surveyed on the types of information their instructors provided on the first day of class. All students reported experiencing lecture, and most $(81.6 \%)$ reported that the lecture focused on course content. Students who reported the highest degrees of initial satisfaction more often came from courses in which instructors had shared information about their educational backgrounds, teaching experience, or lives beyond academia. Self-disclosure of this type of information was reported for roughly two-thirds of the instructors.

The literature previously presented demonstrates that the structure of the first day impacts students' satisfaction with a course and their learning outcomes. These findings align with studies that have shown an association between positive classroom climate and student performance (e.g., Cabrera et al., 1999; McKinney et al., 2006). What instructors do and say in a classroom can help establish a positive learning environment through increasing student buy-in to course activities, reducing stereotype threat, and increasing instructor immediacyinstructor behaviors that serve to decrease the social and emotional distance between the instructor and students (e.g., Croizet and Claire, 1998; Spencer et al., 1999; Witt et al., 2004; Creasey et al. 2009; Austin, 2015). Given the many goals that might be addressed on the first day (creating community, establishing policy, etc.), how instructors choose to spend this time influences what they can accomplish during this class period and sends signals to students regarding instructors' priorities. For example, if instructors spend most of their time lecturing about content, they may miss an early opportunity to establish the type of positive learning environment that fosters student success.

Given the prior focus on student preferences in psychology courses and lack of observation-based information on what instructors do and say on the first day, we aimed to 1) determine how STEM instructors balance their time between content and noncontent topics and 2) characterize the messages these instructors use to establish learning environments on the first day of a course. We pursued these goals by observing and analyzing the first day of 23 introductory STEM courses at three universities using inductive coding and the noncontent Instructor Talk framework (Seidel et al., 2015; Harrison et al., 2019). We focused on introductory STEM courses, as opposed to upper-division courses, because students often leave STEM majors between the first and second years, indicating that students' experiences in these first-year courses may be vital to their persistence (Seymour and Hewitt, 1997; Seymour and Hunter, 2019). Introductory STEM courses also have a reputation as barriers to student retention and diversity in STEM (Mervis, 2011). Moreover, students often experience a large instructional shift between high school and college introductory STEM courses, which may contribute to students' course expectations and concerns (Brown et al., 2017; Akiha et al., 2018; Meaders et al., 2019, 2020). In richly characterizing the first day of class, we sought to gain insights into how this class period can set the tone for the entire course and student experiences within STEM programs.

\section{METHODS}

\section{Faculty Participants}

Participants were recruited through voluntary, yearlong, faculty professional development programs that supported effective, data-driven teaching practices in introductory STEM classes. All three universities included in this study are research-intensive and doctoral-granting institutions located in the United States. Two of the universities are public, and the third is both public and private. Collectively, these faculty taught 23 introductory-level courses across 10 STEM disciplines. Five courses had multiple instructors, whereas the rest had only a single instructor. To protect identities of courses and instructors and for ease of communication, we refer to each course as if it had only a single instructor and do not delineate coding or quotes between individual instructors for a course. We video-recorded the first day of class for all courses 
TABLE 1. Summary of the two coding strategies, data visualization, and statistical tests.

\begin{tabular}{|c|c|c|}
\hline & Topics: coded each second of a class period & Instructor Talk: coded for presence/absence at 1-minute intervals ${ }^{\mathrm{a}}$ \\
\hline \multirow[t]{2}{*}{ Coding } & $\begin{array}{l}\text { Noncontent (e.g., Policies and Basic } \\
\text { Information) }\end{array}$ & $\begin{array}{l}\text { See Supplemental Table } 2 \text { for codes; all Instructor Talk codes either positively } \\
\text { phrased or negatively phrased }\end{array}$ \\
\hline & STEM Content & \\
\hline \multirow[t]{2}{*}{ Data visualization } & Trends across instructors: box plot & Trends across instructors: box plot \\
\hline & Trends for individual instructors: heat map & Trends for individual instructors: heat map \\
\hline Statistical tests & $\begin{array}{l}\text { Hierarchical agglomerative cluster analysis; } \\
\text { Kruskal-Wallis rank sum tests using } \\
\text { cluster output }\end{array}$ & $\begin{array}{l}\text { Pearson correlation tests between instructor's total percentage of 1-minute } \\
\text { intervals for each category and their average COPUS profiles }\end{array}$ \\
\hline
\end{tabular}

anstructor Talk could be present during coverage of either noncontent or content topic periods. If present during content coverage, Instructor Talk consisted of messaging accompanying content delivery (e.g., comments encouraging student questions related to content).

in Fall 2018 using a single camera placed at the back of the lecture hall, and we used two strategies for coding, outlined in Table 1.

\section{Coding for Topics}

We used an inductive coding approach to identify the various topics, including STEM content and noncontent, discussed on the first day. We analyzed the videos using this lens to identify how instructors chose to use their time on the first day. Authors C.L.M. and A.K.L. developed the codes for this analysis by watching three first-day videos and creating an initial list of topics. Authors A.K.L. and J.K.S. then further refined this list by writing definitions for each topic, coding randomly selected sections of videos, and then discussing and iteratively revising each topic and definition to align their thinking (final codebook is provided in Supplemental Table 1). Once the topics were well-defined, J.K.S. watched all of the first-day videos and labeled each second with a topic from the list accounting for all of the class time. For any periods of time that were challenging to assign, J.K.S. and A.K.L. discussed these sections and came to a consensus.

\section{Piloting and Modifying the Instructor Talk Framework}

To categorize what instructors say on the first day of class unrelated to content, we used the Instructor Talk framework, which was developed while observing biology courses over an entire semester (Seidel et al., 2015; Harrison et al. 2019). Instructor Talk is language used by the instructor to establish the learning environment (e.g., building the instructor-student relationship, establishing classroom culture), but it is not directly related to the content taught in the course. This framework focuses on messaging that instructors provide, and previous work has shown that Instructor Talk is more prevalent on the first day compared with the rest of the semester (Seidel et al., 2015). The framework also serves as a codebook that consists of a list of codes organized into categories (see Supplemental Table 2). Because "framework" is the broader term, we will use it instead of "codebook" throughout the article.

Before we began coding the videos of the first day of class, two coders (A.K.L. and C.L.M.) assessed the utility of the Instructor Talk framework by watching and discussing three videos. After each video, the coders described what was captured or inconsistent with the Instructor Talk framework, revising categories and codes to align with our sample (e.g., accounting for our interdisciplinary sample by removing specific references to biology in two codes: Building a Biology Community among Students and Connecting Biology to the Real World and Career). Additional examples of how codes were changed are provided in Supplemental Methods 1.

Next, the coders watched four additional videos to test the revised framework. While coding these videos and reviewing the initial notes, the coders further altered the framework to align with what was observed during the first day and to ensure that each category reflected a discrete theme based on our understanding and application of the codes. The final, revised Instructor Talk framework, showing changes from the original framework, can be found in Supplemental Table 2. Overall, our final framework remained highly similar to the original framework, with most of the modifications being about the organization of codes within larger categories.

\section{Coding Using the Instructor Talk Framework}

There were three stages to the coding process for Instructor Talk. First, videos were divided into 1-minute intervals similar to a segmented observation protocol, such as the Classroom Observation Protocol for Undergraduate STEM (COPUS; Smith et al., 2013), and every minute was coded with all codes that occurred. While previous publications relied on transcripts of audio recordings (Seidel et al., 2015; Harrison et al., 2019), we used video in order to see the classroom context, which allowed us to better understand times when instructors were not speaking and the activity that was happening at the time of each statement.

Second, C.L.M. and A.K.L. independently watched and coded the 1-minute intervals for the presence or absence of positively phrased Instructor Talk framework codes. Throughout the individual coding process, each coder watched all videos at least twice and rewatched sections as needed. While coding, coders took notes about what occurred in each interval and the reasons for their coding choices. The coders then met and discussed each minute, rewatched intervals as necessary, came to consensus for how to code the intervals, and marked any instances of Instructor Talk not captured by the framework as Other. Consensus coding is a common practice for data for which different interrater reliability calculations are prohibited by the data format or quantity, such as not having sufficient amounts of data to have a test data set or having codes that are used infrequently (e.g., Stemler, 2004; Harry et al., 2005). During these meetings, the coders took additional notes to describe the range of statements that fell under a given code. 
Third, an expansion to the Instructor Talk framework to include negatively phrased talk was published during our analysis; thus, our coding for negatively phrased talk involved a different method (Harrison et al., 2019). During the process of taking notes on each 1-minute interval, the coders paid attention to instances of negatively phrased talk. Thus, C.L.M. and A.K.L. individually returned to the videos to code for the presence and absence of the negatively phrased Instructor Talk codes, relying on their prior notes and rewatching intervals as necessary. Again, the coders met and came to consensus about the use of the negatively phrased codes. Coders were conservative in their assignment of negatively phrased codes, mirroring the methods from the original framework (Harrison et al., 2019). In instances when it was unclear whether an idea was negatively phrased, it was assumed to be positively phrased, as was done in Harrison et al. (2019).

Finally, we used the notes made while coding and our in-depth knowledge of the videos to identify broader themes. As part of this sense-making process, we focused on identifying any themes that spanned across codes or ideas that regularly occurred in the Other code (Saldaña, 2015). We chose not to develop new codes for ideas in the Other category (e.g., discussing academic honesty policies), as they were too specific or did not align well with the original Instructor Talk framework. This process allowed us to better elaborate how instructors used codes to achieve shared goals and how they differed in their use of certain codes and to identify new ideas that had not arisen prominently outside the first day.

\section{Characterizing Class Teaching Practices with COPUS}

To characterize the instructional practices used by the participating faculty, we used the COPUS (Smith et al., 2013) and the COPUS Analyzer tool (Stains et al., 2018) to generate COPUS profiles for each instructor for both the first day of class and the subsequent four to five class periods. The COPUSprofiles tool uses COPUS results to categorize a class period into one of three clusters: didactic, interactive, or student-centered teaching practices. The faculty included in our study exhibited a wide range of COPUS profiles on the first day as well as in subsequent class periods (Supplemental Figure 1).

\section{Data Visualization and Statistical Analysis}

All analyses were performed in R (RStudio Team, 2016; $\mathrm{R}$ Core Team, 2019). We used the ggplot2 and RColorBrewer packages (Neuwirth, 2014; Wickham, 2016) to create box plots that provided visualizations of the overall time instructors spent on topics and the percentage of 1-minute intervals instructors spent on Instructor Talk. The box plots provided a method of identifying the most common categories of topics and Instructor Talk and visualizing the mean, median, and variation within each coding category. We then used the gplots package (Warnes et al., 2020) to create heat maps showing how individual instructors spent time on topics and Instructor Talk. The heat maps allowed us to explore whether there were patterns in how individual instructors structured the first day of class.

Because the heat maps of topics pointed to the presence of two groups of instructors, we applied hierarchical agglomerative cluster analysis using the gplots package in $\mathrm{R}$ (Warnes et al., 2020) with Euclidean distance values and weighted-pair group methods with arithmetic means. This analysis focused only on identifying clusters of instructors based on topics covered. We used approaches similar to the analyses described in Zagallo et al. (2019) by performing the analyses multiple times with different linkage algorithms and comparing the resulting dendrograms to identify consistent faculty clusters.

Once we established two clusters based on topic patterns, we explored whether there were differences based on other variables between the groups. Differences in topics covered during the first day could be due to external constraints, such as class period length, course size, or university, or might be attributable to the instructional strategies instructors will use later in the semester. Instructors in our study taught courses of either 50- or 75+-minute length, which we designated as "short" or "long" class periods, respectively. We assigned instructors who ended their classes early to either 50- or $75+$-minute class periods based on the scheduled class time. Course sizes varied between 20 and 565 students, and we divided these into three categories: small ( $<50$ students), medium (50-110 students), and large ( $>110$ students) based on designations outlined in Freeman et al. (2014). Finally, we calculated an average COPUS profile from four to five subsequent class periods to generalize each instructor's overall instructional practices (further described in Supplemental Methods 2). We then used the kruskal.test function to perform Kruskal-Wallis rank-sum tests comparing instructors from the two output clusters based on either class period length, course size, instructional practices during the semester, and university affiliation. The Kruskal-Wallis rank-sum test is a nonparametric test that can be used to identify whether ordinal dependent variables (cluster group) have similar rankings across categorical independent variables (course characteristic variables), allowing for three or more levels within the independent variable (McDonald, 2014).

Finally, the heat map of Instructor Talk indicated that one category was driving variation among instructors, so we did not conduct cluster analyses. To understand how Instructor Talk might be used to set up course teaching practices, we used the corr.test function to calculate pairwise correlations between the percentage of 1-minute intervals with individual categories of Instructor Talk and instructors' average COPUS profiles (Supplemental Methods 2). For this analysis, we tested the correlation of each positively phrased category with instructional practices and collapsed the negatively phrased categories into one negatively phrased variable that represented the total percentage of 1-minute intervals that an instructor used any negatively phrased talk.

\section{RESULTS \\ STEM Instructors Vary in How They Structure the First Day of Class}

Across 23 different STEM courses, we identified nine topics covered by instructors on the first day: eight noncontent topics plus STEM content (Figure 1 and Supplemental Table 1). The most prevalent topic was Policies and Basic Information; all instructors dedicated time to discussing this noncontent topic, spending on average $38 \%$ (SD $\pm 20 \%$ ) of their time on this topic (Figure 1A). The second most common activity was covering STEM Content. Although the instructors overall dedicated an average of $18 \%$ (SD $\pm 20 \%$ ) of time to STEM 
A

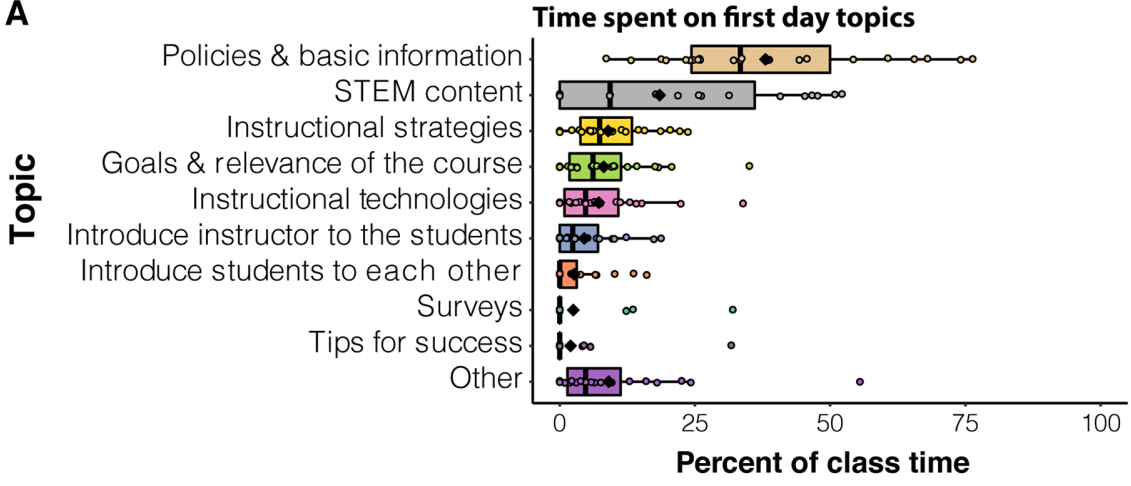

B

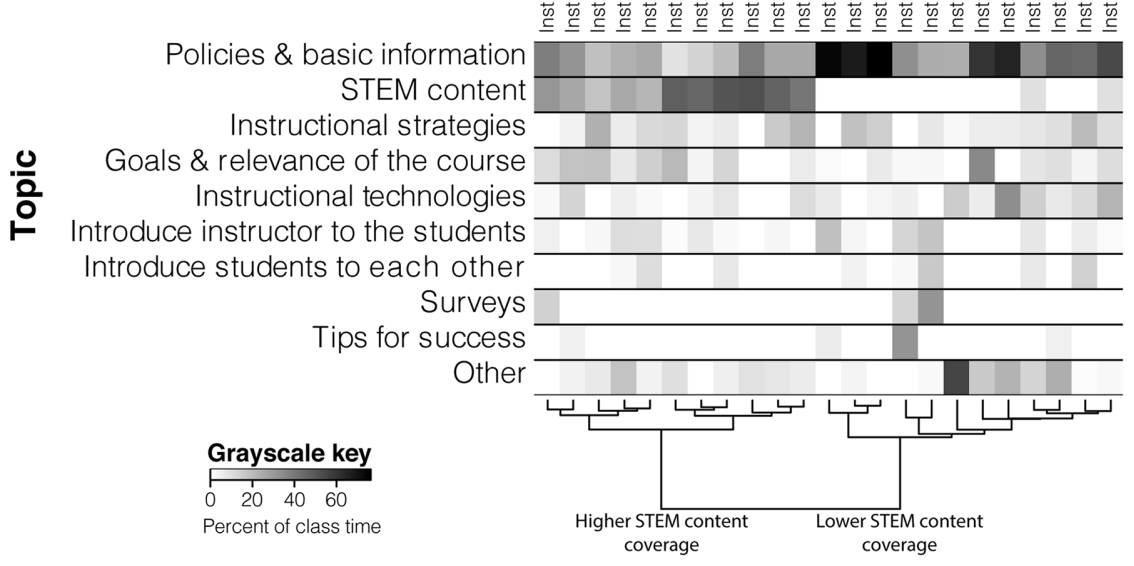

FIGURE 1. Time spent on first-day topics. (A) Box plots of the total percentage of time spent on each topic. Boxes represent the interquartile range (IQR) for each topic. Whiskers represent 1.5 times the IQR. Lines within each box represent the median, and diamonds represent the mean for that talking point. Circles represent the data from each of the 23 classes and are included to show the spread of time within each topic. (B) Heat map depicting how individual instructors structure their class periods. Each column depicts the topics covered by one instructor. Values (black-to-white scale) indicate the total percentage of in-class time instructors spent on a particular topic. Instructors are ordered according to their clustering in the dendrogram below the heat map, calculated by using hierarchical agglomerative cluster analysis. The two clusters are labeled as "Higher STEM content coverage" and "Lower STEM content coverage."

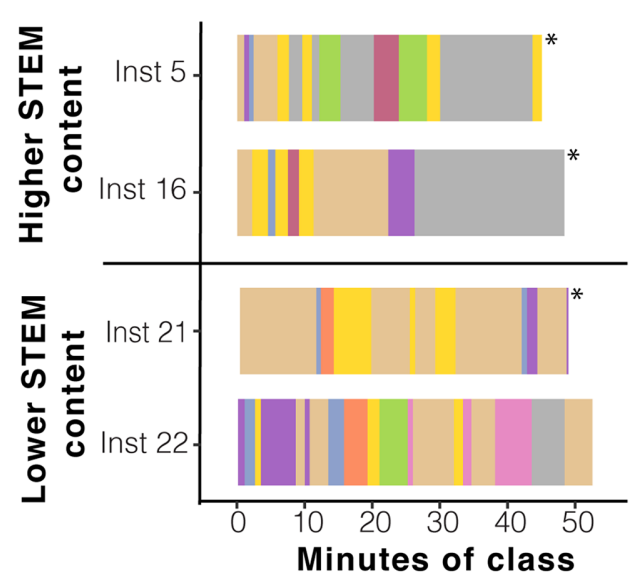

Topics
Policies \& basic information
STEM content
Instructional strategies
Goals \& relevance of the course
Instructional technologies
Introduce instructor to students
Introduce students to each other
Surveys
Tips for success
Overlapping topics
Other
Dead time

FIGURE 2. Timeline of topics in four classes. Randomly selected, 50-minute classes are shown from the higher and lower STEM Content clusters. Colors indicate when the instructor (abbreviated "Inst.") was discussing a particular topic, and classes that ended early are denoted with an asterisk. All instructors are shown in Supplemental Figure 2.
Content, only $56 \%$ of the instructors covered this topic. Other topics covered to a lesser extent included introducing Instructional Strategies or Instructional Technologies, discussing the Goals and Relevance of the Course, taking time to Introduce Instructor to the Students or Students to Each Other, discussing or taking course Surveys, or providing Tips for Success. As the heat map in Figure 1B indicates, there was great variation across instructors in terms of how they structured the first day.

We used cluster analysis to identify patterns of topics covered among our instructor sample (Figure 1B). Two groups of instructors emerged from this analysis: one group dedicated a large amount of time to introducing Policies and Basic Information and little to no time on STEM Content (lower STEM content coverage group) and a second group balanced their time between Policies and Basic Information and STEM Content (higher STEM content coverage group). We investigated whether the differences in clustering were associated with any course characteristics including differences in available class time, course size, university affiliation, and the instructional practices used later by the instructor as determined by the distribution of COPUS profiles for four to five class periods after the first day (Supplemental Methods 2). We found no significant differences between the lower and higher STEM content coverage groups based on these variables using Kruskal-Wallis tests (Supplemental Table 3), suggesting that the amount of policy or content included during the first day is an instructional choice rather than being based upon these course characteristics.

Looking more closely at the topics covered, we found that instructors covered an average of $5.2(\mathrm{SD} \pm 1.4)$ different topics out of the nine identified, and no instructors discussed all of the topics (Supplemental Table 4). Furthermore, instructors typically did not complete one topic before moving on to the next. Instead, they regularly switched between topics with an average of $12.7(\mathrm{SD} \pm 6.2)$ changes throughout a class period (Supplemental Table 4). However, once instructors began covering STEM Content, they often covered the content continuously until finished. Figure 2 illustrates the degree to which instructors changed topics by providing timelines of the first day of class for four instructors (all instructors shown in Supplemental Figure 2). 

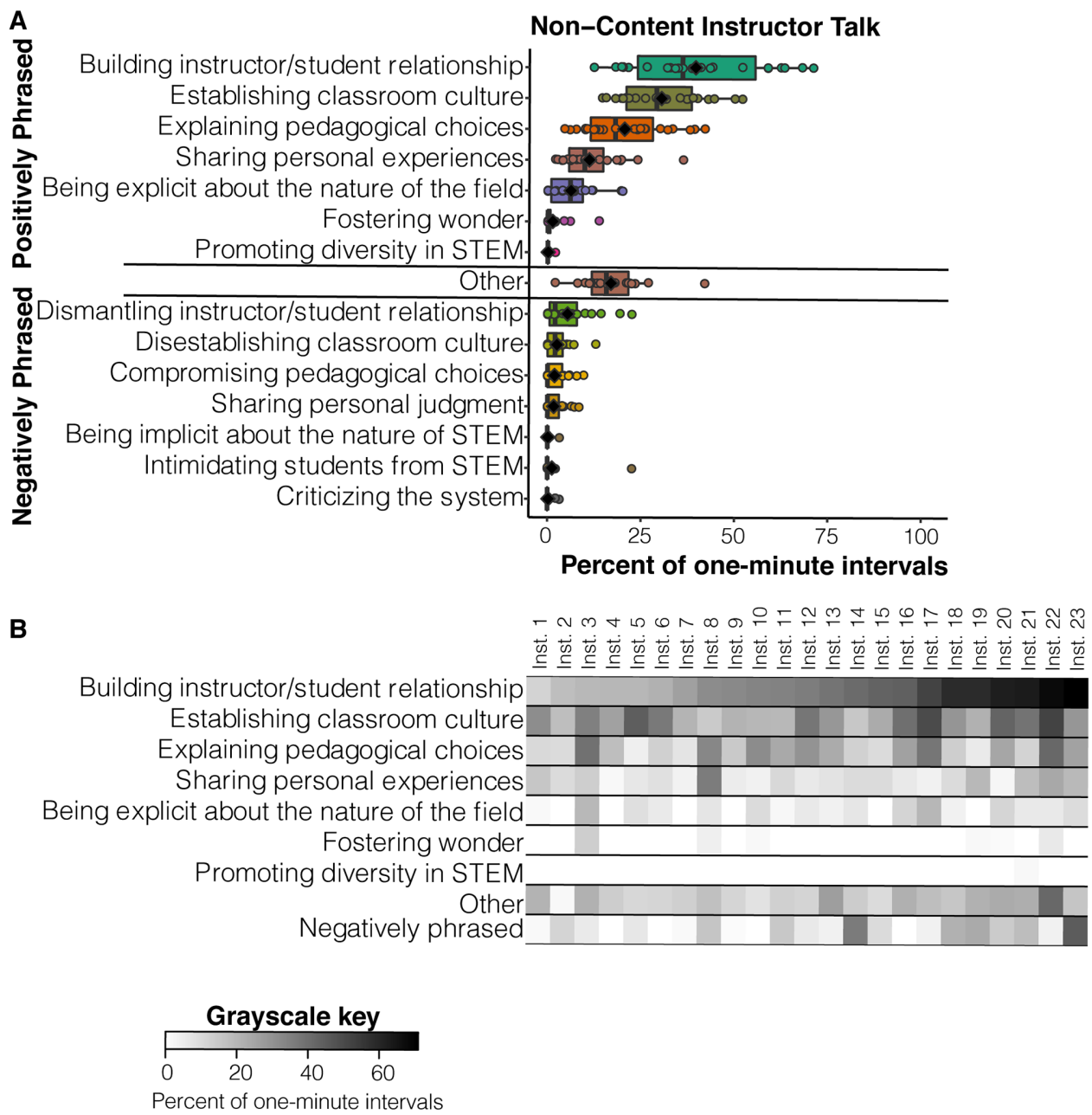

FIGURE 3. Time spent on Instructor Talk. (A) Box plot of the percentage of time instructors spent on each Instructor Talk category. Boxes represent the interquartile range (IQR) for each category. Whiskers represent 1.5 times the IQR. Lines within each box represent the median, and diamonds represent the mean for that talking point. Circles represent the data points from the 23 instructors (abbreviated "Inst.") and are included to show the spread of time within each category. (B) Heat map showing the percentage of 1-minute intervals each instructor spent on Instructor Talk categories. Each column represents one instructor. Instructors are ordered by their amount of the category Building Instructor-Student Relationship, as it was the category with greatest variation among instructors. The seven different negatively phrased categories are collapsed to one negatively phrased column, as they each had low frequencies.

\section{Instructors Use a Variety of Instructor Talk to Establish a Positive Environment}

In addition to the topics discussed on the first day, we also applied the Instructor Talk framework (Supplemental Table 2) to the same course videos to capture the messages that faculty imparted on the first day. All 23 instructors used positive talk during the first day, and positively phrased categories were coded more frequently than negatively phrased categories (Figure 3A). The heat map in Figure 3B illustrates variation in the use of Instructor Talk across all instructors.

Overall, the most common positively phrased and negatively phrased categories were related to building or dismantling instructor-student relationships. These categories also had the widest variation, with instructors spending an average of $39 \%$ (SD $\pm 18 \%$ ) of 1-minute intervals on Building Instructor-Student Relationship and an average of $5 \%$ (SD $\pm 6 \%$ ) on Dismantling Instructor-Student Relationship (Figure 3). The category Building Instructor-Student Relationship included codes such as Revealing Secrets to Success: Studying, Expressing Empathy for Students, and Demonstrating Desire for Students to Learn/ Succeed. This positively phrased talk category had a significant negative correlation, $r(21)=-0.44, p=0.04$, with the instructional practices used by instructors later in the semester. In other words, instructors who dedicated a higher percent of time to Building Instructor-Student Relationship on the first day typically used more traditional or didactic instructional practices later in the semester (Supplemental Table 5). Meanwhile, the category Dismantling Instructor-Student Relationship included the codes Ignoring Student Challenges, Assuming Poor Behaviors from Students, and Making Public Judgments about Students. Negatively phrased talk occurred in an average of $11 \%$ (SD $\pm 12 \%$ ) of 1 -minute intervals, with two instructors using negatively phrased talk in $30 \%$ of 1-minute intervals, and four instructors using no negatively phrased talk (Figure 3). Negatively phrased talk had a significant negative correlation with instructional practices as categorized by the average COPUS 
profiles, $r(21)=-0.45, p=0.03$ (Supplemental Table 5), indicating that negatively phrased talk was less common among instructors who used interactive lecture or more student-centered practices.

Each positively phrased category is further composed of several codes (Supplemental Table 2). There was variation in code use across instructors, with six codes used by all instructors in at least 1 minute during the first day (Supplemental Figure 3). These codes included 1) Revealing Secrets to Success: Encouraging Students to Use Outside Resources, 2) Revealing Secrets to Success: Other, 3) Pre-framing Classroom Activities, 4) Building a Community among Students, 5) Supporting Learning through Teaching Choices, and 6) Recounting Personal Information.

\section{Different Instructor Talk Codes Can Be Used for the Same Purpose}

In the following sections, we describe broader themes that emerged from our qualitative discourse analysis and supply example quotes to provide a greater description of how instructors used the first day of class. We found that STEM instructors can share similar instructional goals but leverage different Instructor Talk to achieve those goals. The most common occurrence of this relates to explaining the relevance of the course to students. Some instructors used Fostering Wonder by trying to establish interest in the subject matter on its own merits. One of the instructors began the class by describing how only Earth has biology, saying,

Earth is different. It's unique. It's got green, right? It's got plants, animals, and microorganisms. And these organisms have all these crazy properties that aren't reflected in these other [science] disciplines right? So, Earth has biology.Instructor 22

The instructor went on to state that biology is interesting because it is constantly changing through evolution. Other instructors introduced the course by Connecting the Course to the Real World or Careers. For example, some instructors explained that the skills students would learn in class would be important for their future. One computer science instructor said the following about the importance of learning to program:

Futurists and economists will probably tell you that the jobs of today ... will not exist 10, 15, 20 years from now. Once they've perfected automated driving cars and they've become ubiquitous, there goes $10 \%$ of the working population-their purpose for working. What do we do?... But in any case, you will be part of that. And you need to decide: am I going to be masters of those machines or am I going to be one of the ones made obsolete by them?-Instructor 20

\section{Statements Varied in Depth}

Multiple codes could vary in depth from including specific instructions or guidance for students to making more general statements without detailed directions. The most notable variation occurred within the codes focused on Revealing Secrets to Success. Instructors either provided detailed tips for students or made more general statements. For example, when Revealing
Secrets to Success related to studying, instructors could provide specific advice, such as,

Read your notes. If you're organizing your notes, that's good. Study groups are really good. I'll try to set up a chat or special group on [online system] that you can use to set up study groups amongst yourselves. Active participation in your notes, in your studying, is better than passively going through notes.-Instructor 23

In this example, the instructor gave students multiple recommendations on how to study and suggested a means for them to set up study groups through their online system for the course. Some instructors provided tips without as many specific suggestions on how to follow through with the advice: "Don't be afraid to try different study techniques. This material can be challenging and what you've done in the past may not work ... don't be afraid to try different things to find what does work for you" (Instructor 11).

\section{One Instructor Promoted Diversity in STEM}

Only one instructor was coded as using the category Promoting Diversity in STEM (Figure 3 and Supplemental Figure 3). This instructor emphasized that diversity and inclusion were important to them. They described wanting students to feel comfortable and respected in the classroom and encouraged students to come to the instructor with concerns or requests. However, this instructor's comments were also general and requested that students come to them for help, as exemplified by them saying,

I try so hard to make this an inclusive, respectful classroom. If there's ever anything I can do to make it more so ... if there's something more I can do (or less) then please tell me because this is something I care deeply about.-Instructor 21

\section{Mixed Messages May Be Present in Negatively Phrased Talk}

Some instructors provided students with information or messages that could benefit them while at the same time using negatively phrased Instructor Talk. These combinations of positive intent and negatively phrased statements may give students mixed messages about the classroom environment and instructors' priorities. For example, Instructor 23 encouraged students to read the syllabus by saying, "Read your syllabus. What every professor loves is somebody coming in and asking 50 questions that all were answered by 'it's in the syllabus." However, due to the particular phrasing used, the instructor may have been Discouraging Students from Asking Questions. A few instructors also used negatively phrased talk when discussing how difficult students should expect the course to be. Instructor 23 also said, “The course is not easy. Don't mean to scare you off. The course is not easy, but that's okay because [subject] is not an easy major and we are here to help you." This statement is considered negative because, while the aim may be to establish student expectations, it could also leave students concerned about the course and worried about it being overly challenging.

Instructors also had mixed messages about studying, learning, and getting good grades. For example, Instructor 18 was Focusing on the Grade, which is a negatively phrased code, while providing advice to limit students' workload, saying, in 
part, "A lot of people tend to do really well in the course without that regular homework being done; especially if they're juniors or seniors, you've figured out how to do all this." In this example, the instructor focused on the grade by emphasizing that getting a good grade was the goal of the course. The instructor did not otherwise mention learning course material or skills as what students should be aiming to accomplish. Then the instructor tried to be helpful by saying that upperclass students may not have to do the extra practice of homework, a suggestion that further detracts from learning as the course goal.

\section{Novel Messages Found on the First Day}

Implementing the Instructor Talk framework on the first day in a variety of STEM courses allowed us to identify messages that did not arise prominently in prior observational studies, which looked across the entire semester (Seidel et al., 2015; Harrison et al., 2019). In some cases, these new messages related to an Instructor Talk category but did not align with a previously established code, so we coded them as Other (Figure 3 and Supplemental Table 6). For example, approximately half of the instructors tried to build the instructor-student relationship with additional messages such as sharing that they wanted to learn students' names or providing examples of topics that students could discuss with them during office hours, such as class subjects or shared interests. For example, Instructor 1 said, "If you're interested in becoming a teacher, and you're interested in pedagogy, come talk to me."

Another novel message was discussing academic honesty; $52 \%$ of the instructors in our sample did this on the first day. When discussing academic honesty, some instructors focused on how the instructor had ways to catch students cheating or that academic integrity cases were frustrating to the instructor, because they took up a lot of their time. Instructor 13 focused on how academic integrity cases took time from their work with other students: "We don't like to have academic integrity cases. It takes a lot of our time. It distracts us from teaching and from working with other students." Other instructors were more encouraging and sympathized with difficulties students have related to academic honesty. Some instructors acknowledged that academic honesty may be a fuzzy concept to students and one that needs to be clarified. One instructor said,

We've had some issues with cheating and then we started talking to the students and talking amongst ourselves and what we figured out was that there's a lot of people who were cheating but they didn't realize they were cheating. So, at the beginning of every class, I like to discuss what cheating is and what is okay and what is not okay because it does get a little confusing.--Instructor 9

This instructor also described how students can make mistakes and cheat by accident, especially when working on group projects, and tried to help students learn how to avoid cheating. Other instructors mentioned that waiting until the last minute to do homework could lead students to cheat in order to finish on time and recommended that students start their assignments early.

Approximately one-fifth of the instructors leveraged course alumni to aid in providing tips for students. For example, instructors shared feedback and advice from previous students that they had collected through course evaluation comments or by seeking out electronic submissions of advice from former students. One instructor introduced advice from former students by saying,

One of the things that I asked my students last semester, at the very end of the semester, was to give me a piece of advice. If they had to start [the course] over again, what is something they wish[ed] they had known?-Instructor 11

Some instructors also had former students currently serving as learning or teaching assistants spend time on the first day discussing what helped them be successful in the class.

\section{DISCUSSION}

The goals of this study were to characterize 1) how STEM instructors structure their time between content and noncontent topics on the first day of class and 2) what Instructor Talk occurs that might contribute to students' first-day experience. Unlike previous studies of the first day of class, we observed courses in multiple STEM disciplines and focused on what instructors do and say rather than students' preferences. This focus allowed us to characterize the extent to and manner in which instructors start to develop a positive course climate (Cabrera et al., 1999; Creasey et al., 2009; Austin 2015). We discuss these findings and the implications they have for professional development programs, instructors, and future research.

We found that half of the instructors did not cover any STEM Content, and those who did cover STEM Content typically spent less than half of the first day on it (Figure 1). The limited level of STEM Content coverage observed in this study aligns with students' preferences for structure of the first day (Perlman and McCann, 1999; Henslee et al., 2006). Indeed, several survey studies of psychology students have shown that they dislike the introduction of content on the first day. Moreover, limiting the amount of content covered provides instructors an opportunity to use other ways to establish a positive climate and rapport with students. All instructors included a variety of noncontent topics (Figure 1), and many switched regularly between them (Figure 2, Supplemental Figure 2, and Supplemental Table 4). Instructors spent the most time on building instructor-student relationships, followed by establishing a classroom culture (Figure 3). They also used much more positively phrased than negatively phrased talk, consistent with results from previous work (Seidel et al., 2015; Harrison et al., 2019). Studies in psychology have demonstrated long-lasting positive impacts on students when instructors spend some time developing a sense of community during the first day and use an upbeat tone. Our findings thus suggest that most STEM faculty in this sample provided their students with a positive and influential first-day experience.

One finding that emerged from these data is the large variation that we observed in the ways instructors structure the first day (Figures 1 and 2). This variety suggests that best practices for the first day may be complex and context dependent. Instructors cannot cover every detail or fully establish the classroom environment or expectations in a single class period; therefore, they must make trade-offs and prioritize based on what they think is most important for the first day. For example, 
instructors may choose to spend time on Policies and Basic Information instead of STEM Content. Being judicious with time on the first day could allow an instructor to focus on topics that have the greatest potential to positively influence student experiences. The variation seen for noncontent topics across courses also suggests a need for further insights on how to prioritize the different noncontent topics as well as guidance for implementing each topic. This prioritization and guidance may be especially true for tackling issues that are potentially sensitive or challenging for instructors to address on the first day, such as academic integrity or Promoting Diversity in Science.

Our study also reveals a high level of switching between topics (Figure 2, Supplemental Figure 2, and Supplemental Table 4). Each course may benefit from first day-specific objectives to help provide a cohesive message for students and ensure efficient use of class time. For example, instructors may have an objective of giving students advice about how to study, and they can use this goal to provide specific suggestions for studying, such as the formation of study groups. The reflective process of developing these objectives could also provide clarity about what an instructor thinks is most important to cover and what could wait until a future class period. Moreover, the development of these objectives and the related specific suggestions may help instructors avoid nonspecific or mixed messages in which they use negatively phrased talk with positive intent. Teaching and learning centers and professional development programs could implement workshops to help guide faculty through this reflection and creation of first day-specific learning objectives.

This study provides data on how the first day of class is used in practice and draws attention to specific areas in which instructors may need additional support and resources. There were some discussion points that were covered by many instructors, but the instructors took different approaches to presenting them. For example, academic honesty was covered by many instructors, but some instructors emphasized the distraction caused by academic dishonesty, whereas others tried to empathize with students. It is unclear what the impact of these varying approaches could have on students' experiences. Therefore, instructors could benefit from research into how students respond to different presentations of certain discussion points.

Some topics were covered sparingly, possibly because they are challenging and instructors do not have sufficient training or resources to help them present on those topics. Only one instructor included general statements promoting diversity. Instructors may need to seek additional resources for help in establishing an appropriate classroom climate on the first day (e.g., Salazar et al., 2009; Armstrong, 2011; Tanner, 2013). In addition, while more research is needed on how to support particular groups of students on the first day, there are resources available that could be applied beginning on the first day, such as those for cultural competence (e.g., Tanner and Allen, 2007) and LGBTQ+ students (e.g., Cooper et al., 2020). Depending on the course subject, instructors may need to address certain groups of students or prepare students to cover particular content in class, such as the perceived conflict between religion and evolution (e.g., Barnes and Brownell, 2017).

Finally, every instructor spent some time Pre-framing Classroom Activities and explaining how their teaching choices supported student learning (Supplemental Figure 3). Students have been shown to respond positively to faculty encouraging engagement in active-learning activities (e.g., Finelli et al., 2018), and this messaging represents one strategy that instructors can use to help students understand and value course learning activities (Seidel and Tanner, 2013; Brazeal and Couch, 2017). Furthermore, there are resources that describe how the first day could be used to promote student buy-in with active learning or to promote student engagement in the course in general (Chasteen, 2013, 2020).

\section{Limitations}

Although this study provides one of the first empirical investigations about how STEM college instructors are using the first day of class, there are certain considerations for interpretation of these results. First, we are focusing on Instructor Talk, thereby not including nonverbal cues or other frameworks, such as instructor immediacy (Gorham, 1988). This work also differs from recent work that focused on the ways biology content is discussed in class (Betz et al., 2019). In addition, by coding 1-minute intervals rather than individual statements, we may have underestimated the differences in time spent on coded items, because instructors making several statements concerning a subject over the course of 1 minute would be coded the same as instructors making a single statement in that interval. Our sample of instructors may also provide some biases, as they were all voluntary participants in a professional development program focused on pedagogy; however, it is important to note that all first-day videos were taken before the first meeting for the program. Finally, we were unable to compare between disciplines or institution type due to the size of the sample, the wide distribution of disciplines, and the similarity in institution type across the three institutions. Future work could consider discipline- or institution-specific differences in Instructor Talk.

\section{Future Directions}

Our work to characterize the first day of class advances the field by providing information to guide faculty reflection and establishing a foundation for future research. Faculty professional development programs can use the coding schemes from this work to observe and document the first day of classes, and faculty can reflect on how what they do and say aligns with their first-day objectives. The results presented here can serve as a reference point for how an individual faculty member's course compares with courses taught by the broader community. In addition, professional development programs could encourage faculty to listen to their own or another instructor's class videos and look for types of negatively phrased Instructor Talk, and then work together to develop more positive wording.

The topics and Instructor Talk delivered on the first day likely reveal an instructor's implicit values, and more research is needed to understand how specific instructional decisions relate to an instructor's broader goals and teaching philosophy. Furthermore, some topics and types of Instructor Talk may be more important than others for establishing course expectations and climate. More research is also needed to understand what STEM students notice and respond to on the first day, with specific attention to how student reactions vary between demographic groups or students with different levels of college experience. By better understanding how to deliver an effective first 
day, instructors have the potential to elicit lasting impressions and set students on a positive track toward success.

\section{ACKNOWLEDGMENTS}

This work was supported by the National Science Foundation under grants DUE-1712074, DUE-1712060, and DUE-1347814; the NebraskaSCIENCE Program of Excellence at the University of Nebraska-Lincoln; and the Provost's Gateway Initiative and the Center for Teaching Innovation at Cornell University. This research was considered exempt from institutional review: University of Maine protocol 2017-05-12, University of Nebraska-Lincoln protocol 20170617341, and Cornell University protocol 1806008047.

\section{REFERENCES}

Akiha, K., Brigham, E., Couch, B. A., Lewin, J., Stains, M., Stetzer, M. R., ... \& Smith, M. K. (2018). What types of instructional shifts do students experience? Investigating active learning in science, technology, engineering, and math classes across key transition points from middle school to the university level. Frontiers in Education, 2, 68.

Anderson, D. M., McGuire, F. A., \& Cory, L. (2011). The first day: It happens only once. Teaching in Higher Education, 16(3), 293-303.

Armstrong, M. A. (2011). Small world: Crafting an inclusive classroom (no matter what you teach). Thought and Action, 2011, 51-61.

Austin, V. L. (2015). Elements of good teaching and good teachers: A theoretical framework and effective strategies for special educators. Journal of the American Academy of Special Education Professionals, 7. 20.

Barnes, M. E., \& Brownell, S. E. (2017). A call to use cultural competence when teaching evolution to religious college students: Introducing religious cultural competence in evolution Education (ReCCEE). CBE-Life Sciences Education, 16(4), es4.

Betz, N., Leffers, J. S., Thor, E. E. D., Fux, M., de Nesnera, K., Tanner, K. D., \& Coley, J. D. (2019). Cognitive construal-consistent instructor language in the undergraduate biology classroom. CBE-Life Sciences Education, 18(4), ar63.

Brazeal, K. R., Brown, T. L., \& Couch, B. A. (2016). Characterizing student perceptions of and buy-in toward common formative assessment techniques. CBE-Life Sciences Education, 15(4), ar73.

Brazeal, K. R., \& Couch, B. A. (2017). Student buy-in toward formative assessments: The influence of student factors and importance for course success. Journal of Microbiology \& Biology Education, 18(1).

Brown, T. L., Brazeal, K. R., \& Couch, B. A. (2017). First-year and non-first-year student expectations regarding in-class and out-of-class learning activities in introductory biology. Journal of Microbiology \& Biology Education, 18(1)

Cabrera, A. F., Nora, A., Terenzini, P. T., Pascarella, E., \& Hagedorn, L. S. (1999) Campus racial climate and the adjustment of students to college: A comparison between White students and African-American students. Journal of Higher Education, 70(2), 134-160.

Chasteen, S. (2013, January 9). First day of class: Getting students on board with active learning. Retrieved May 14, 2020, from https://blog.sciencegeekgirl.com/2013/01/09/the-first-day-of-class-getting-students-onboard-with-active-learning-physicsed

Chasteen, S. (2020, May 13). How can I set the stage for student engagement in an active learning classroom, from the first day? Retrieved May 14, 2020, from www.physport.org/recommendations/Entry.cfm?ID=101223

Cooper, K. M., Auerbach, A. J. J., Bader, J. D., Beadles-Bohling, A. S., Brashears, J. A., Cline, E., ... \& Heinz, H. M. (2020). Fourteen recommendations to create a more inclusive environment for LGBTQ+ individuals in academic biology. CBE-Life Sciences Education, 19(3), es6.

Creasey, G., Jarvis, P., \& Gadke, D. (2009). Student attachment stances, instructor immediacy, and student-instructor relationships as predictors of achievement expectancies in college students. Journal of College Student Development, 50(4), 353-372.

Croizet, J. C., \& Claire, T. (1998). Extending the concept of stereotype threat to social class: The intellectual underperformance of students from low socioeconomic backgrounds. Personality and Social Psychology Bulletin, 24(6), 588-559.

DiClementi, J. D., \& Handelsman, M. M. (2005). Empowering students: Class-generated course rules. Teaching of Psychology, 32(1), 18-21.

Eskine, K. E., \& Hammer, E. (2017). Students' perspectives on the first day of class: A replication. International Journal for the Scholarship of Teaching and Learning, 11(1), 5-10. https://doi.org/10.20429/ijsotl.2017.110105

Finelli, C. J., Nguyen, K., DeMonbrun, M., Borrego, M., Prince, M., Husman, J., ... \& Waters, C. K. (2018). Reducing student resistance to active learning: Strategies for instructors. Journal of College Science Teaching, 47(5), 80-91.

Freeman, S., Eddy, S. L., McDonough, M., Smith, M. K., Okoroafor, N., Jordt H., \& Wenderoth, M. P. (2014). Active learning increases student performance in science, engineering, and mathematics. Proceedings of the National Academy of Sciences USA, 111(23), 8410-8415. https:// doi.org/10.1073/pnas.1319030111

Friedrich, G. W., Cawyer, C. S., \& Storey, J. L. (1993). Together again for the first time: A descriptive study of the first day of class. Annual Meeting of the International Communication Association held in May 27-31, 1993 at Washington, DC

Gorham, J. (1988). The relationship between verbal teacher immediacy behaviors and student learning. Communication Education, 37(1), 40-53.

Harrison, C. D., Nguyen, T. A., Seidel, S. B., Escobedo, A. M., Hartman, C., Lam, K., .. \& Balukjian, B. (2019). Investigating Instructor Talk in novel contexts: Widespread use, unexpected categories, and an emergent sampling strategy. CBE-Life Sciences Education, 18(3), ar47.

Harry, B., Sturges, K. M., \& Klingner, J. K. (2005). Mapping the process: An exemplar of process and challenge in grounded theory analysis. Educational Researcher, 34(2), 3-13.

Henslee, A. M., Burgess, D. R., \& Buskist, W. (2006). Student preferences for first day of class activities. Teaching of Psychology, 33(3), 189-191.

Hermann, A. D., Foster, D. A., \& Hardin, E. E. (2010). Does the first week of class matter? A quasi-experimental investigation of student satisfaction. Teaching of Psychology, 37(2), 79-84. https:// doi.org/10.1080/00986281003609314

Laws, E. L., Apperson, J. M., Buchert, S., \& Bregman, N. J. (2010). Student evaluations of instruction: When are enduring first impressions formed? North American Journal of Psychology, 12(1), 81-92.

McDonald, J. H. (2014). Handbook of biological statistics (3rd ed.). Baltimore, MD: Sparky House Publishing. Retrieved January 4, 2021, from www.biostathandbook.com/testchoice.html

McGinley, J. J., \& Jones, B. D. (2014). A brief instructional intervention to increase students' motivation on the first day of class. Teaching of Psychology, 41(2), 158-162. https://doi.org/10.1177/0098628314530350

McKinney, J. P., McKinney, K. G., Franiuk, R., \& Schweitzer, J. (2006). The college classroom as a community: Impact on student attitudes and learning. College Teaching, 54(3), 281-284.

Meaders, C. L., Lane, A. K., Morozov, A. I., Shuman, J. K., Toth, E. S., Stains, M., .. \& Smith, M. K. (2020). Undergraduate student concerns in introductory STEM courses: What they are, how they change, and what influences them. Journal for STEM Education Research 3, 195-216. https:// doi.org/10.1007/s41979-020-00031-1

Meaders, C. L., Toth, E. S., Lane, A. K., Shuman, J. K., Couch, B. A., Stains, M., \& Smith, M. K. (2019). "What will I experience in my college STEM courses?" An investigation of student predictions about instructional practices in introductory courses. CBE-Life Sciences Education, 18(4), $\operatorname{ar} 60$

Mervis, J. (2011). Weed-out courses hamper diversity. Science, 334(6061), 1333 Neuwirth, E. (2014). RColorBrewer: ColorBrewer Palettes ( $R$ package version 1.1-2). Retrieved from https://cran.r-project.org/web/packages/ RColorBrewer/index.html Retrieved 01/04/2021

Nilson, L. B. (2010). Teaching at its best: A research-based resource for college instructors (3rd ed.). San Francisco, CA: Jossey-Bass.

Perlman, B., \& McCann, L. I. (1999). Student perspectives on the first day of class. Teaching of Psychology, 26(4), 277-279. https://doi.org/10.1207/ S15328023TOP260408

R Core Team. (2019). R: A language and environment for statistical computing. Vienna, Austria: R Foundation for Statistical Computing. Retrieved January 4, 2021, from www.R-project.org 
Robinson, D. (2019). Engaging students on the first day of class: Studentgenerated questions promote positive course expectations. Scholarship of Teaching and Learning in Psychology, 5(3), 183-188. https://doi .org/10.1037/stl0000139

RStudio Team. (2016). RStudio: Integrated development for R. Boston, MA: RStudio, Inc. Retrieved January 4, 2021, from www.rstudio.com

Salazar, M. D. C., Norton, A. S., \& Tuitt, F. A. (2009). Weaving promising practices for inclusive excellence into the higher education classroom. In Nilson, L. B., \& Miller, J. E. (Eds.), To improve the academy (pp. 208-226). San Francisco, CA: Jossey-Bass.

Saldaña, J. (2015). The coding manual for qualitative researchers. London, England: Sage.

Sax, L. J., Blaney, J. M., Lehman, K. J., Rodriguez, S. L., George, K. L., \& Zavala C. (2018). Sense of belonging in computing: The role of introductory courses for women and underrepresented minority students. Social Sciences, 7(8), 122.

Schinske, J. N., Perkins, H., Snyder, A., \& Wyer, M. (2016). Scientist spotlight homework assignments shift students' stereotypes of scientists and enhance science identity in a diverse introductory science class. $C B E-$ Life Sciences Education, 15(3), ar47.

Seidel, S. B., Reggi, A. L., Schinske, J. N., Burrus, L. W., \& Tanner, K. D. (2015). Beyond the biology: A systematic investigation of noncontent Instructor Talk in an introductory biology course. CBE-Life Sciences Education, 14(4), ar43.

Seidel, S. B., \& Tanner, K. D. (2013). "What if students revolt?"-Considering student resistance: Origins, options, and opportunities for investigation. CBE-Life Sciences Education, 12(4), 586-595.

Seymour, E., \& Hewitt, N. M. (1997). Talking about leaving: Why undergraduates leave the sciences. Boulder, CO: Westview Press.

Seymour, E., \& Hunter, A. B. (2019). Talking about leaving revisited. New York: Springer.

Smith, M. K., Jones, F. H., Gilbert, S. L., \& Wieman, C. E. (2013). The Classroom Observation Protocol for Undergraduate STEM (COPUS): A new instrument to characterize university STEM classroom practices. CBE-Life Sciences Education, 12(4), 618-627.
Spencer, S. J., Steele, C. M., \& Quinn, D. M. (1999). Stereotype threat and women's math performance. Journal of Experimental Social Psychology, 35(1), 4-28.

Stains, M., Harshman, J., Barker, M. K., Chasteen, S. V., Cole, R., DeChenne-Peters, S. E., .. \& Levis-Fitzgerald, M. (2018). Anatomy of STEM teaching in North American universities. Science, 359(6383), 1468-1470

Stemler, S. E. (2004). A comparison of consensus, consistency, and measurement approaches to estimating interrater reliability. Practical Assessment, Research, and Evaluation, 9(1), 4.

Tanner, K., \& Allen, D. (2007). Cultural competence in the college biology classroom. CBE-Life Sciences Education, 6(4), 251-258.

Tanner, K. D. (2013). Structure matters: Twenty-one teaching strategies to promote student engagement and cultivate classroom equity. CBE-Life Sciences Education, 12(3), 322-331.

Trujillo, G., \& Tanner, K. D. (2014). Considering the role of affect in learning: Monitoring students' self-efficacy, sense of belonging, and science identity. CBE-Life Sciences Education, 13(1), 6-15.

Warnes, G. R., Bolker, B., Bonebakker, L., Gentleman, R., Huber, W., Liaw, A., ... \& Venables, B. (2020). gplots: Various $R$ programming tools for plotting data (R package version 3.0.1.2.). Retrieved January 4, 2021, from https://CRAN.R-project.org/package=gplots

Wickham, H. (2016). ggplot2: Elegant graphics for data analysis. New York: Springer-Verlag.

Wilson, J. H., \& Wilson, S. B. (2007). The first day of class affects student motivation: An experimental study. Teaching of Psychology, 34(4), 226230. https://doi.org/10.1080/00986280701700151

Witt, P. L., Wheeless, L. R., \& Allen, M. (2004). A meta-analytical review of the relationship between teacher immediacy and student learning. Communication Monographs, 71(2), 184-207.

Zagallo, P., McCourt, J., Idsardi, R., Smith, M. K., Urban-Lurain, M., Andrews, T. C., ... \& Prevost, L. B. (2019). Through the eyes of faculty: Using personas as a tool for learner-centered professional development. CBE-Life Sciences Education, 18(4), ar62. 